\title{
A Reaction Network Model for Phenol Oxidation in Supercritical Water
}

\author{
Sudhama Gopalan and Phillip E. Savage \\ Dept. of Chemical Engineering, The University of Michigan, Ann Arbor, MI 48109
}

\begin{abstract}
Dilute aqueous solutions of phenol were oxidized in a flow reactor at 420,440, 460 and $480^{\circ} \mathrm{C}$ at $250 \mathrm{~atm}$. Phenol disappearance kinetics followed the trends exhibited by previously published data obtained at $T<420^{\circ} \mathrm{C}$. By merging the two sets of data, a global rate law for phenol disappearance kinetics valid between 380 and $480^{\circ} \mathrm{C}$ was determined to be rate $=10^{2.34} \exp (-12.4 / \mathrm{RT})[\phi \mathrm{OH}]^{0.85}\left[\mathrm{O}_{2}\right]^{0.50}\left[\mathrm{H}_{2} \mathrm{O}\right]^{0.42}$. Undesired multiring products, whose formation was reported previously at the lower temperatures, continued to form in high selectivities at these higher temperatures. Reaction products were classified into three categories: dimers, gases, and a remainder that included products from ring-opening reactions. A global reaction network that describes the transformation of phenol into these product groups was developed. Steps in the network are: parallel oxidation paths for phenol that form dimers and ring-opening and other products, secondary decomposition of dimers to ring-opening and other products, and oxidation of the ring-opening and other products to carbon oxides. The experimental product yields were used to determine optimal values for the reaction orders and rate constants for each step in the network. This quantitative reaction model shows that dimerization is the dominant primary path for phenol consumption. High temperatures and long residence times reduce the concentration of dimers in the reactor effluent and maximize the gas yield. High oxygen concentrations also increase the gas yield. The quantitative reaction network model is consistent with previously published product yields for $T=380-420^{\circ} \mathrm{C}$.
\end{abstract}

\section{Introduction}

Supercritical water oxidation (SCWO) is being developed as an economically viable and ecologically safe ultimate destruction technology to treat aqueous waste streams containing 1 to $20 \%$ organics by weight. The organic pollutants react with oxygen in an aqueous environment at reaction conditions beyond the critical point of water $\left(T_{c}=374^{\circ} \mathrm{C}, P_{c}=218\right.$ bar) to give $\mathrm{CO}_{2}$ and $\mathrm{H}_{2} \mathrm{O}$ as the ultimate products. Supercritical water facilitates dissolution of both organic compounds and oxygen, thereby creating a single homogeneous phase for the oxidation.

High destruction and removal efficiencies for SCWO have been established for a wide variety of model pollutants as well as for real and simulated wastes (Modell, 1989). More recently, several kinetics studies have been conducted on model pollutants like phenol (Thornton and Savage, 1992a),

Correspondence concerning this article should be addressed to P. E. Savage. $o$-chlorophenol (Li et al., 1993), $p$-chlorophenol (Yang and Eckert, 1988), 2,4-dichlorophenol (Lee et al., 1990), acetic acid (Savage and Smith, 1995; Lee et al., 1990), and pyridine (Crain et al., 1993). These studies have focused primarily on determining global rate laws for the disappearance of the organic compound. Departing from this trend, $\mathrm{Li}$ et al. (1992) obtained global rate laws for the formation of $\mathrm{CO}_{2}$ from the oxidation of phenol and $o$-chlorophenol.

Thornton et al. (1991) identified several multiring products (such as dibenzofuran, 2- and 4-phenoxyphenol, dibenzo-pdioxin, and 2,2'-biphenol) from the oxidation of phenol in supercritical water at $380^{\circ} \mathrm{C}$. The formation of such dimers is important because some of these are potentially more toxic than the reactant, phenol. In subsequent work, Thornton and Savage (1992b) reported the concentrations of many of these products, developed a reaction network that described the formation of these multiring species from phenol, and deter- 
mined pseudo-first-order rate constants for oxidation at $380^{\circ} \mathrm{C}$ and $278 \mathrm{~atm}$. In response to Thornton et al. (1991) reporting the formation of dibenzofuran and dibenzo-p-dioxin from the SCWO of phenol, Swallow and Killilea (1992) reported that at temperatures between 600 and $630^{\circ} \mathrm{C}$ SCWO achieved $99.99 \%$ destruction efficiency of a mixture of dioxins and furans. The authors conjectured that there was a competition between reactions that produce dioxins and furans at low temperatures and those that destroy them at higher temperatures, with destruction reactions being favored at their conditions. Moreover, the authors claimed that dioxins and furans do not form from their precursors at the higher temperatures.

Our current state of knowledge regarding dioxin and furan formation during SCWO of phenolic wastes is limited to a quantitative model for only one specific set of conditions at a low temperature of $380^{\circ} \mathrm{C}$. Furthermore, Swallow and Killilea (1992) suggest that the reaction paths for phenol observed at $380^{\circ} \mathrm{C}$ do not represent the chemistry at commercial SCWO conditions. Hence, we extended the previous studies on phenol oxidation to temperatures up to $480^{\circ} \mathrm{C}$. In this study, we first develop a global rate law for phenol disappearance from the new phenol conversion data. We then focus on the higher molecular weight or dimeric products of phenol and develop reaction networks that suitably represent the qualitative trends observed experimentally for the conversion of phenol into its chief oxidation products. Model discrimination on the basis of quality of fits of the respective models to experimental data is performed to determine the best candidate. This quantitative reaction model is then used to identify strategies to minimize the dimer concentrations.

\section{Experimental Section}

We conducted phenol oxidation experiments in an isothermal, isobaric tubular flow reactor at temperatures between 420 and $480^{\circ} \mathrm{C}$ and at $250 \mathrm{~atm}$. High pressure pumps deliver feed streams containing the organic compound and oxygen dissolved in water. These aqueous streams are preheated separately in two $1 / 16$-in. $(1.6-\mathrm{mm})$ OD feed lines, and they mix in a Hastelloy $\mathrm{C}-276$ cross at which the reactor originates. The reactor is constructed of $1 / 8-\mathrm{in}$. (3.2-mm) OD Hastelloy C-276 tubing and has a length of $4 \mathrm{~m}$. The reactor assembly is housed in a temperature-controlled fluidized sand bath that maintains isothermality to within $1^{\circ} \mathrm{C}$. Upon leaving the heated zone of the sand bath, the reactor effluent is cooled and then depressurized and separated into vapor and liquid fractions. The reactor operation approximated plugflow behavior as evidenced by meeting the criteria of Cutler et al. (1988).

Unreacted phenol in the reactor effluent is quantified to within $\pm 2 \%$ using reversed-phase, isocratic, high-performance liquid chromatography (HPLC). We used a C18 column, a mobile phase of acetonitrile:water $(2: 5 \mathrm{v} / \mathrm{v})$, and UV detection at $210 \mathrm{~nm}$. Higher molecular weight products, which are present in much lower concentrations than phenol, are extracted into dichloromethane and then concentrated using a protocol developed on the basis of EPA Method 604 for the quantification of phenols (Federal Register, 1984). Twenty $\mathrm{mL}$ of the aqueous reactor effluent is successively extracted with three $10-\mathrm{mL}$ aliquots of dichloromethane to ensure nearly complete removal of organic components from the aqueous phase. The extract is then concentrated to approximately $1 \mathrm{~mL}$ by evaporation at $50^{\circ} \mathrm{C}$ in a Kuderna-Danish micro concentrator with biphenyl added as an internal standard. The concentrated samples are analyzed by gas chromatography (GC) using a $12 \mathrm{~m} \times 0.2-\mathrm{mm}$ OD HP-1 capillary column and splitless injection. The temperature program includes a $4^{\circ} \mathrm{C} / \mathrm{min}$ ramp from $35^{\circ} \mathrm{C}$ to $120^{\circ} \mathrm{C}$, followed by a $2^{\circ} \mathrm{C} / \mathrm{min}$ ramp to $160^{\circ} \mathrm{C}$ and a $10^{\circ} \mathrm{C} / \mathrm{min}$ ramp to $250^{\circ} \mathrm{C}$. Based on replicated analyses, we estimate the error in the entire extraction, concentration, and quantification process as $\pm 20 \%$. Product identities are established using mass spectrometric detection and quantification is performed with flame ionization detection. GC analyses confirmed that the phenol feed solutions and the biphenyl internal standard were free of the multiringed species found in the product spectrum. Quantification of $\mathrm{CO}$ and $\mathrm{CO}_{2}$ is accomplished with an online gas chromatograph with thermal conductivity detection. Additional details regarding the reactor and analyses have been previously reported (Thornton and Savage, 1990, 1992a,b; Thornton et al., 1991; Li et al., 1992, 1993).

\section{Kinetics of Phenol Disappearance}

We conducted experiments at $420,440,460$ and $480^{\circ} \mathrm{C}$ at a pressure of $250 \mathrm{~atm}$, with most experiments done at $T=$ $460^{\circ} \mathrm{C}$. The phenol and oxygen concentrations varied between 0.03 and $0.39 \mathrm{mmol} / \mathrm{L}$ and 1.6 and $9.4 \mathrm{mmol} / \mathrm{L}$, respectively, as shown in Table 1 . The global rate for phenol $(\phi \mathrm{OH}) \mathrm{de}-$ struction may be expressed as

$$
\text { rate }=k(T)[\phi \mathrm{OH}]^{a}\left[\mathrm{O}_{2}\right]^{b}\left[\mathrm{H}_{2} \mathrm{O}\right]^{c}
$$

where $a, b$, and $c$ are the reaction orders of phenol, oxygen, and water, respectively, $k(T)$ is the reaction rate coefficient, which can be expressed in Arrhenius form as

$$
k(T)=A \exp \left(-\frac{E_{a}}{R T}\right)
$$

where $E_{a}$ is the activation energy, and $A$ is the preexponential factor.

To determine the global kinetic parameters, we performed a nonlinear regression analysis using SimuSolv, a modeling and simulation package developed by Dow Chemical Co. (Steiner et al., 1990). Employing a reduced-gradient searchoptimization routine, we fitted the following model

$$
X=1-\left(1-(1-a) k(T) \tau[\phi \mathrm{OH}]_{0}^{a-1}\left[\mathrm{O}_{2}\right]_{0}^{b}\left[\mathrm{H}_{2} \mathrm{O}\right]_{0}^{c}\right)^{1 /(1-a)}
$$

to the experimental phenol conversions in Table 1. Equation 3 follows from integration of the plug-flow reactor design equation using the global rate law in Eq. 1 and the definition of conversion. Li et al. (1992) provide a more detailed derivation of Eq. 3. Here $X$ is the conversion of phenol, and $\tau$ is the reactor residence time. The concentration subscript 0 represents values at the reactor entrance. The $\mathrm{O}_{2}$ concentration is assumed constant throughout the reaction since $\mathrm{O}_{2}$ 
Table 1. Summary of Phenol Oxidation Experiments

\begin{tabular}{|c|c|c|c|c|c|c|c|c|c|}
\hline \multirow[b]{2}{*}{$\begin{array}{c}T \\
\left({ }^{\circ} \mathrm{C}\right)\end{array}$} & \multirow[b]{2}{*}{$\begin{array}{c}P \\
(\mathrm{~atm})\end{array}$} & \multirow{2}{*}{$\begin{array}{l}\text { Phenol } \\
\text { Conc. } \\
\text { (mol/L) }\end{array}$} & \multirow[b]{2}{*}{$\begin{array}{c}\tau \\
(s)\end{array}$} & \multirow{2}{*}{$\begin{array}{c}\text { Oxygen } \\
\text { Conc. } \\
(\mathrm{mol} / \mathrm{L})\end{array}$} & \multirow{2}{*}{$\begin{array}{l}\text { Water } \\
\text { Conc. } \\
(\mathrm{mol} / \mathrm{L})\end{array}$} & \multirow{2}{*}{$\begin{array}{c}\text { Phenol } \\
\text { Conv. } \\
(\%)\end{array}$} & \multicolumn{3}{|c|}{ Product Selectivity } \\
\hline & & & & & & & $\begin{array}{c}\text { Dimers } \\
(\%)\end{array}$ & $\begin{array}{c}\text { Gases } \\
(\%)\end{array}$ & $\begin{array}{c}\text { Others } \\
(\%)\end{array}$ \\
\hline 420 & 250 & $1.40 \mathrm{E}-04$ & 6.6 & $7.63 \mathrm{E}-03$ & 7.33 & 10.68 & 54.49 & & \\
\hline 420 & 250 & $1.40 \mathrm{E}-04$ & 9.4 & $5.57 \mathrm{E}-03$ & 7.33 & 14.95 & 59.20 & 12.80 & 27.99 \\
\hline 420 & 250 & $1.40 \mathrm{E}-04$ & 11.7 & $5.56 \mathrm{E}-03$ & 7.33 & 18.22 & 50.33 & 11.10 & 38.57 \\
\hline 420 & 250 & $1.40 \mathrm{E}-04$ & 15.2 & $5.55 \mathrm{E}-03$ & 7.33 & 22.36 & 39.20 & 10.98 & 49.82 \\
\hline 420 & 250 & $2.80 \mathrm{E}-04$ & 8.7 & $9.22 \mathrm{E}-03$ & 7.33 & 13.88 & & 19.58 & \\
\hline 440 & 250 & $1.22 \mathrm{E}-04$ & 5.8 & $6.61 \mathrm{E}-03$ & 6.39 & 11.17 & 33.75 & & \\
\hline 440 & 250 & $1.22 \mathrm{E}-04$ & 8.2 & $4.92 \mathrm{E}-03$ & 6.39 & 16.49 & 50.86 & 12.51 & 36.62 \\
\hline 440 & 250 & $1.22 \mathrm{E}-04$ & 10.1 & $4.93 \mathrm{E}-03$ & 6.39 & 17.23 & 51.32 & 15.38 & 33.30 \\
\hline 440 & 250 & $2.41 \mathrm{E}-04$ & 7.7 & $7.89 \mathrm{E}-03$ & 6.39 & 20.03 & & 44.03 & \\
\hline 460 & 250 & $2.99 \mathrm{E}-05$ & 6.6 & $3.55 \mathrm{E}-03$ & 5.78 & 21.82 & 17.12 & 78.57 & 4.31 \\
\hline 460 & 250 & $5.14 \mathrm{E}-05$ & 11.2 & $2.60 \mathrm{E}-03$ & 5.78 & 20.89 & 20.98 & 51.58 & 27.45 \\
\hline 460 & 250 & $5.51 \mathrm{E}-05$ & 8.0 & $9.37 \mathrm{E}-03$ & 5.78 & 27.84 & 12.78 & & \\
\hline 460 & 250 & $7.46 \mathrm{E}-05$ & 5.8 & $1.59 \mathrm{E}-03$ & 5.78 & 8.28 & 47.77 & 37.64 & 14.59 \\
\hline 460 & 250 & $8.30 \mathrm{E}-05$ & 8.0 & $9.36 \mathrm{E}-03$ & 5.78 & 24.96 & 18.85 & 80.71 & 0.45 \\
\hline 460 & 250 & $8.32 \mathrm{E}-05$ & 9.0 & $6.79 \mathrm{E}-03$ & 5.78 & 14.96 & & & \\
\hline 460 & 250 & $1.11 \mathrm{E}-04$ & 5.3 & $4.10 \mathrm{E}-03$ & 5.78 & 11.64 & 49.03 & 26.99 & 23.98 \\
\hline 460 & 250 & $1.12 \mathrm{E}-04$ & 5.3 & $2.13 \mathrm{E}-03$ & 5.78 & 16.72 & & & \\
\hline 460 & 250 & $1.11 \mathrm{E}-04$ & 5.3 & $6.47 \mathrm{E}-03$ & 5.78 & 14.07 & 48.74 & 26.36 & 24.90 \\
\hline 460 & 250 & $1.11 \mathrm{E}-04$ & 5.3 & $9.97 \mathrm{E}-03$ & 5.78 & 19.53 & 29.14 & 29.40 & 41.46 \\
\hline 460 & 250 & $1.10 \mathrm{E}-04$ & 5.4 & $8.81 \mathrm{E}-03$ & 5.78 & 10.80 & & 36.58 & \\
\hline 460 & 250 & $1.11 \mathrm{E}-04$ & 6.4 & $6.56 \mathrm{E}-03$ & 5.78 & 16.92 & 30.11 & 19.22 & 50.67 \\
\hline 460 & 250 & $1.11 \mathrm{E}-04$ & 7.5 & $4.33 \mathrm{E}-03$ & 5.78 & 16.94 & 31.93 & 32.92 & 35.15 \\
\hline 460 & 250 & $1.11 \mathrm{E}-04$ & 9.3 & $4.31 \mathrm{E}-03$ & 5.78 & 19.73 & 31.68 & 32.77 & 35.55 \\
\hline 460 & 250 & $1.11 \mathrm{E}-04$ & 12.2 & 4.33E-03 & 5.78 & 25.75 & 35.27 & 29.53 & 35.20 \\
\hline 460 & 250 & $1.66 \mathrm{E}-04$ & 8.0 & $9.35 E-03$ & 5.78 & 26.13 & 22.77 & 51.64 & 25.59 \\
\hline 460 & 250 & $1.66 \mathrm{E}-04$ & 9.0 & $6.80 \mathrm{E}-03$ & 5.78 & 15.70 & & 52.19 & \\
\hline 460 & 250 & $2.22 \mathrm{E}-04$ & 2.7 & $6.44 \mathrm{E}-03$ & 5.78 & 7.15 & 93.11 & 11.22 & \\
\hline 460 & 250 & $2.21 \mathrm{E}-04$ & 5.0 & $6.44 \mathrm{E}-03$ & 5.78 & 10.14 & 40.98 & 17.58 & 41.44 \\
\hline 460 & 250 & $2.22 \mathrm{E}-04$ & 6.1 & $8.55 \mathrm{E}-03$ & 5.78 & 16.18 & 33.02 & 10.34 & \\
\hline 460 & 250 & $2.22 \mathrm{E}-04$ & 6.8 & $4.37 \mathrm{E}-03$ & 5.78 & 18.60 & 29.85 & 16.59 & \\
\hline 460 & 250 & $2.25 \mathrm{E}-04$ & 11.7 & $6.28 \mathrm{E}-03$ & 5.78 & 16.70 & 25.83 & 26.72 & 47.45 \\
\hline 460 & 250 & $2.78 \mathrm{E}-04$ & 8.0 & $9.35 \mathrm{E}-03$ & 5.78 & 22.34 & 22.62 & 48.13 & 29.25 \\
\hline 460 & 250 & $2.77 \mathrm{E}-04$ & 9.1 & $6.42 \mathrm{E}-03$ & 5.78 & 20.99 & 22.64 & & \\
\hline 460 & 250 & $3.89 \mathrm{E}-04$ & 8.0 & $9.36 \mathrm{E}-03$ & 5.78 & 22.72 & 24.70 & 42.08 & 33.21 \\
\hline 460 & 250 & $3.88 \mathrm{E}-04$ & 9.1 & $6.44 \mathrm{E}-03$ & 5.78 & 22.36 & 22.41 & & \\
\hline 480 & 250 & $1.02 \mathrm{E}-04$ & 4.9 & $3.79 \mathrm{E}-03$ & 5.34 & 12.54 & 35.55 & & \\
\hline 480 & 250 & $1.02 \mathrm{E}-04$ & 6.8 & $4.11 E-03$ & 5.34 & 17.80 & 41.89 & & \\
\hline 480 & 250 & $1.02 \mathrm{E}-04$ & 8.3 & $4.09 \mathrm{E}-03$ & 5.34 & 19.63 & 35.59 & 36.24 & 28.17 \\
\hline 480 & 250 & $1.02 \mathrm{E}-04$ & 10.8 & $4.04 \mathrm{E}-03$ & 5.34 & 24.10 & 33.23 & 38.78 & 27.98 \\
\hline 480 & 250 & $1.97 \mathrm{E}-04$ & 2.8 & $7.75 \mathrm{E}-03$ & 5.34 & 6.60 & & 87.11 & \\
\hline 480 & 250 & $2.04 \mathrm{E}-04$ & 6.3 & $7.75 \mathrm{E}-03$ & 5.34 & 27.68 & & 17.18 & \\
\hline 480 & 250 & $2.04 \mathrm{E}-04$ & 6.3 & $6.67 E-03$ & 5.34 & 48.73 & & 69.08 & \\
\hline
\end{tabular}

was always present in at least $200 \%$ excess of the stoichiometric requirement. Moreover, as phenol conversions are under $30 \%$ in almost all cases, the $\mathrm{O}_{2}$ concentration should remain relatively invariant. Also, since $\mathrm{H}_{2} \mathrm{O}$ constituted at least 99.5 mole $\%$ of the reaction mixture, the $\mathrm{H}_{2} \mathrm{O}$ concentration could be assumed to be invariant from the initial concentration.

The statistical correlation of the Arrhenius parameters with the reaction orders in the global rate law was reduced by regressing these parameters separately. Reaction orders were obtained using data from the 26 experiments at $460^{\circ} \mathrm{C}$. The reaction orders for phenol and oxygen were thus determined as $a=0.86( \pm 0.04)$ and $b=0.50( \pm 0.05)$, respectively, where the numbers in parentheses indicate the standard deviations estimated for the regressed parameters. For this threeparameter (two reaction orders and a rate coefficient) regression, the standard error of estimate or average standard devi- ation for the conversion was 0.017 . This means that model predictions for the phenol conversion at $460^{\circ} \mathrm{C}$ can be expected to be within plus or minus two of these standard deviations (within 3.4\% conversion) approximately $95 \%$ of the time.

The reaction order estimates compare reasonably well with the findings of Thornton and Savage (1992b); namely, firstorder with respect to phenol and one-half order with respect to oxygen. These earlier reaction orders were obtained from data at $380^{\circ} \mathrm{C}$ and $278 \mathrm{~atm}$ using an integral method of analysis. The authors considered only reaction orders for phenol that were multiples of $1 / 2$, so their first-order finding simply implies that the order was closer to 1 than to $1 / 2$ or $3 / 2$. The nonlinear regression technique employed in this article gives more precise results. Hence, we revisited the data of Thornton (1991) using the nonlinear regression protocol to get more precise estimates of reaction orders. Using data from $55 \mathrm{ex}$ - 
periments at $380^{\circ} \mathrm{C}$ and 278 atm we determined the reaction orders for phenol and oxygen to be $0.84( \pm 0.04)$ and 0.49 $( \pm 0.06)$. Since these reaction orders match those obtained from the present data at $460^{\circ} \mathrm{C}$ very closely, the data from Table 1 were merged with the data of Thornton (1991) between 380 and $420^{\circ} \mathrm{C}$ to determine the Arrhenius parameters and a reaction order for water. A single rate law, thus determined, would be applicable for phenol oxidation at supercritical conditions between 380 and $480^{\circ} \mathrm{C}$.

We fixed the phenol order at 0.85 and the oxygen order at 0.5 and determined the remaining rate parameters by a separate regression. Table 2 displays the parameter estimates, standard deviations of these estimates, the standard error of estimate, the symmetric variance-covariance matrix, and the symmetric correlation matrix. The diagonal elements of the variance-covariance matrix are the variances $V_{i i}$ of the parameters, whereas the off-diagonal elements are the covariances $V_{i j}$. The square roots of the variances are often quoted as the error limits of the parameters (in our case, these are the figures enclosed in parentheses). When covariances are overlooked, the uncertainty of the calculated response variable will always be overestimated. The full variance-covariance matrix is necessary for correct estimation of confidence intervals (Héberger et al., 1987). Totally incorrect confidence interval estimates can result from the use of individual uncertainties of the estimated parameters when there is a close correlation between the parameters. Héberger et al. (1987) illustrate this situation with the case of the two-parameter ( $A, E_{a}$ ) regression of the Arrhenius rate coefficient. Using parameter uncertainties alone results in a rectangular confidence interval on a contour map of the sum of squared residuals in the two-dimensional $\left(A, E_{a}\right)$ parameter space. On the other hand, the use of the error propagation law,

$$
\begin{aligned}
V_{k_{i}}=\left(\frac{\partial k_{i}}{\partial A}\right)_{i}^{2} V_{A, A}+2\left(\frac{\partial k_{i}}{\partial A}\right)_{i}\left(\frac{\partial k_{i}}{\partial E_{a}}\right)_{i} V_{A, E_{u}} & \\
& +\left(\frac{\partial k_{i}}{\partial E_{a}}\right)_{i}^{2} V_{E_{a}, E_{a}}
\end{aligned}
$$

which incorporates covariances, results in a smaller elliptical confidence interval.

Table 2. Parameters in Phenol Disappearance Rate Law

\begin{tabular}{ll}
\hline$a$ & 0.85 \\
$b$ & 0.50 \\
$c$ & $0.42 \pm 0.05$ \\
$E_{a}(\mathrm{kcal} / \mathrm{mol})$ & $12.4 \pm 1.0$ \\
$A\left(\mathrm{M}^{-0.77} \mathrm{~s}^{-1}\right)$ & $10^{2.34 \pm 0.28}$ \\
\hline
\end{tabular}

Standard error of estimate 0.038

\begin{tabular}{|c|c|c|c|c|}
\hline $\begin{array}{l}A \\
E_{a} \\
c\end{array}$ & & $\begin{array}{l}A \\
7.71 \mathrm{E}-02 \\
83.4 \\
1.23 \mathrm{E}-02\end{array}$ & $\begin{array}{c}E_{a} \\
1.06 \mathrm{E}+06 \\
48.80\end{array}$ & $2.98 \mathrm{E}-03$ \\
\hline \multicolumn{5}{|c|}{ Correlation Matrix } \\
\hline & & $\begin{array}{c}A \\
1.00 \\
0.99 \\
0.81\end{array}$ & $\begin{array}{c}E_{a} \\
1.00 \\
0.87\end{array}$ & 1.00 \\
\hline
\end{tabular}

Variance-covariance matrix
The correlation matrix, the elements of which can be computed from the variance-covariance matrix as $r_{i j}=$ $V_{i j} / \sqrt{V_{i i} V_{j j}}$, gives the statistical correlation between the parameters. The closer the value of $r_{i j}$ is to unity, the stronger the correlation between the parameters $i$ and $j$. The correlation coefficient values from Table 2 show a close correlation between the Arrhenius parameters $A$ and $E_{a}$, and a smaller degree of correlation of the water order $c$ with the Arrhenius parameters. Consequently, an apparent compensation effect results wherein almost the same fit can be obtained using a larger value for $E_{a}$ together with a larger value for $A$ and/or $c$, or by using smaller values for the parameters (Héberger et al., 1987).

The correlation of the parameter that accounts for pressure effects $(c)$ with the parameters that account for temperature effects $\left(A, E_{a}\right)$ brings to the fore the difficulty in expressing the effect of pressure on the rates of oxidation reactions in supercritical water. We use a reaction order with respect to water as a convenient means of representing this effect of pressure. The influence on the reaction rate is thus that of the water density, which is a function of both temperature and pressure. Near the critical point of water, large changes in density can be achieved with small isothermal pressure changes. This is the feature that was exploited by Thornton and Savage (1992), who examined densities between 0.1 and $0.5 \mathrm{~g} / \mathrm{cm}^{3}$ at $380^{\circ} \mathrm{C}$ and pressures between 188 and $278 \mathrm{~atm}$. At the higher temperatures used in this study $\left(420<T<480^{\circ} \mathrm{C}\right)$, the water density is a distinctly weaker function of both temperature and pressure. The highest pressure at which our flow reactor can be operated safely is 300 atm, so the highest water density that can be obtained within our temperature range is $0.2 \mathrm{~g} / \mathrm{cm}^{3}$. Consequently, the data in Table 1 span a range of water density $\left(0.096 \mathrm{~g} / \mathrm{cm}^{3}<\rho<\right.$ $0.13 \mathrm{~g} / \mathrm{cm}^{3}$ ) that is too narrow to yield a statistically significant water reaction order. Thus, the estimated water order shown in Table 2 primarily results from the Thornton data, which spanned a wider density space. The water order of 0.42 is a significant improvement over the earlier reported value of 0.7 (Thornton and Savage, 1992) and is solely attributable to the improved regression technique.

Figure 1 shows a parity plot of the phenol conversion calculated from the global rate law using the parameters from Table 2 in Eq. 3 against the conversions obtained experimentally. The filled circles represent data at temperatures between 380 and $480^{\circ} \mathrm{C}$, whereas the open squares represent the data of Thornton (1991) at subcritical temperatures $(T=$ $300,340^{\circ} \mathrm{C} ; \rho=0.75,0.65 \mathrm{~g} / \mathrm{cm}^{3}$ ), which were not used in the regression. A perfect fit of the model to the data would result in all the points lying on the $45^{\circ}$ line. The data at supercritical conditions are described well by the model with no systematic trends in residuals. The data at subcritical conditions are also well described by the model for conversions up to about $50 \%$. At higher conversions, however, the model consistently underpredicts the conversion for subcritical conditions. Thus, the model, which works well at supercritical temperatures, breaks down at high conversions when extrapolated to subcritical temperatures and higher densities. This systematic error may be indicative of a shift in reaction mechanism at subcritical conditions.

We also used Eq. 3 and the global rate law parameters from Table 2 to predict the phenol SCWO results of Rice et 


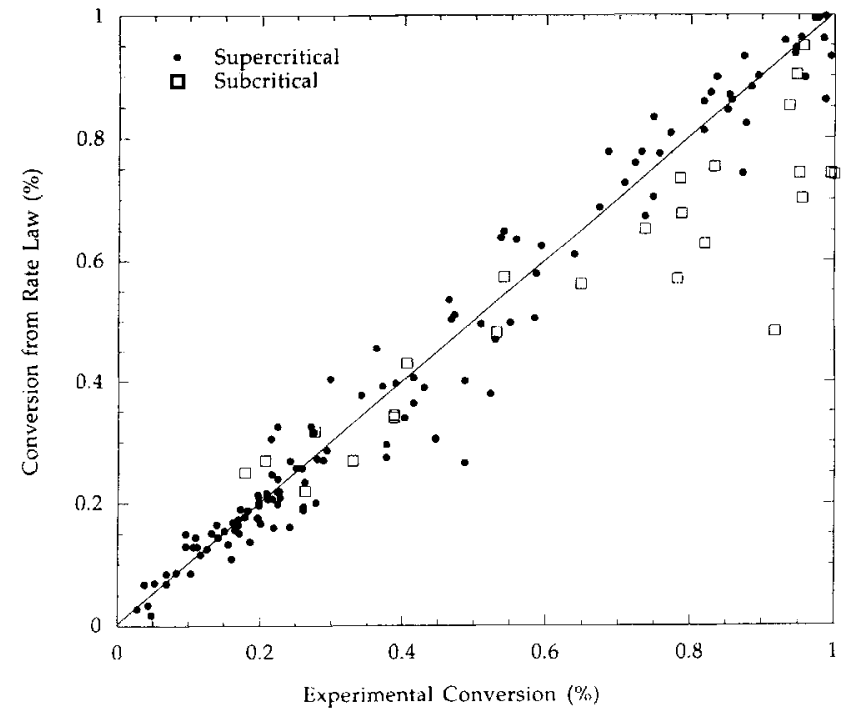

Figure 1. Comparison of global rate law calculations of phenol conversion with experimental values.

al. (1993), and Wightman (1981). Figure 2 compares the rate constants predicted from our global rate law for phenol disappearance with the data of Rice et al. (1993), and Wightman (1981) in the form of an Arrhenius plot. The plot also shows the data reported in this article and the data of Thornton (1991) with the discrete point representing the mean value and the error bars representing one standard deviation about the mean. It is clear that our rate law underpredicts the rate constants of Rice et al. (1993) and Wightman (1981), but never by more than a factor of 4 . There are at least two reasons why the present rate law might not perfectly predict the kinetics of Rice et al. (1993) and Wightman (1981). One is that the conditions used in their work were significantly different from those reported in this article. Rice et al. (1993) employed higher temperatures between 505 and $585^{\circ} \mathrm{C}$ and reac-

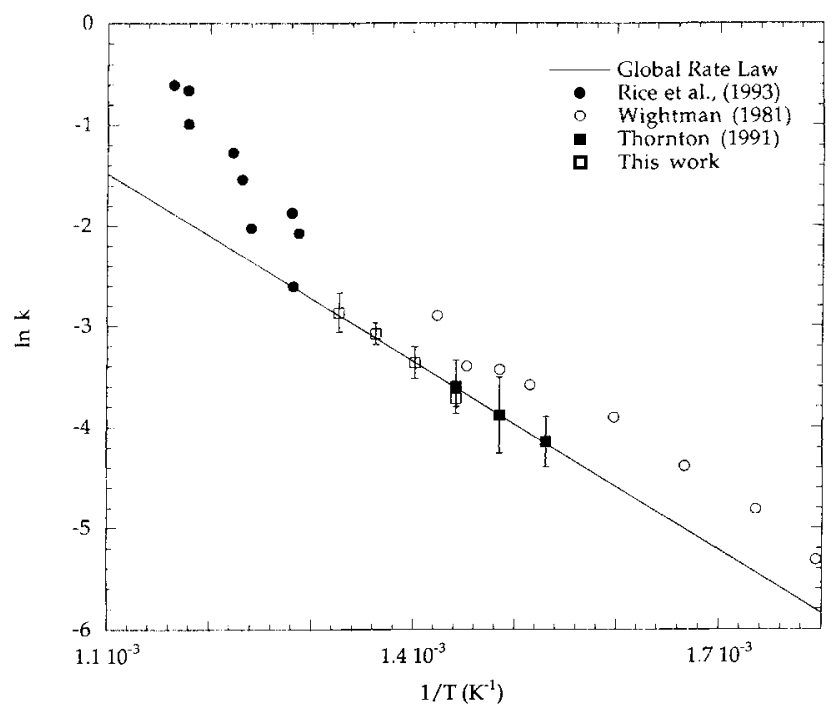

Figure 2. Comparison of phenol oxidation data of Rice et al. (1993) and Wightman (1981) with present work. tant concentrations that were an order of magnitude higher than in the current work. Most of the experiments of Wightman (1981) used higher densities and subcritical temperatures. The second reason is that in both studies the oxygen concentrations were calculated and not measured directly as in our study. Wightman (1981) used a published correlation to determine oxygen solubility in water, and this value can differ from measured solubilities. On the other hand, Rice et al. (1993) used $\mathrm{H}_{2} \mathrm{O}_{2}$ as the oxidant in their study. $\mathrm{H}_{2} \mathrm{O}_{2}$ is preheated separately in their reactor configuration and is assumed to decompose to water and molecular oxygen in the preheater section.

\section{Phenol Oxidation Network Model}

A major goal of this study was to investigate the formation of multiring products from phenol at temperatures higher than those previously used $\left(T>420^{\circ} \mathrm{C}, P=250 \mathrm{~atm}\right)$. At these higher temperatures, the water density was around $0.1 \mathrm{~g} / \mathrm{cm}^{3}$, which is representative of the density at proposed commercial SCWO conditions $\left(T=400-650^{\circ} \mathrm{C}, P=250\right.$ atm). Whether reactions in supercritical water proceed by ionic or free-radical mechanisms is strongly influenced by density (Antal et al., 1987). The previous work (Thornton et al., 1991) employed densities as high as $0.5 \mathrm{~g} / \mathrm{cm}^{3}$ (at $T=380^{\circ} \mathrm{C}, P=$ $278 \mathrm{~atm}$ ); conditions that could favor ionic reaction mechanisms as opposed to the radical mechanisms favored at the lower densities. In this sense, the reaction mechanism operative at the conditions of this study should be representative of the mechanism under commercial SCWO conditions.

That multiring products continue to be detected in the reactor effluent at temperatures between 420 and $480^{\circ} \mathrm{C}$ is evident from the selectivities reported in Table 1. Here, the four major phenol dimers identified by GC-MS (see the total ion chromatogram in Figure 3), namely, dibenzofuran, 2-phenoxyphenol, 2,2'-biphenol, and 4-phenoxyphenol, are grouped together. The dimer selectivity therefore represents the $\%$ of the reacted carbon that is present in dimeric products. Similarly, the selectivity to gases represents the $\%$ of reacted carbon that appears as carbon oxides. Species concentrations were transformed from the units of Table $1(\mathrm{~mol} / \mathrm{L})$ to moles of carbon per liter so that we could calculate the selectivities for each product group on the basis of carbon content. The data in Table 1 show that dimers and gases constitute the major portion of the reaction product spectrum. The balance of the carbon, which constitutes the category "others," most likely appears in single-ring products (such as 2,3-dihydro$1 \mathrm{H}$-indene-1-one, as seen in Figure 3), and products of ringopening reactions (such as organic acids). Thornton and Savage (1990) identified several single-ring products and organic acids from phenol oxidation. In this study, we found only traces of organic acids.

The data of Thornton and Savage (1992b) for phenol SCWO, and Li et al. (1992) for SCWO of 2-chlorophenol show some general trends for product selectivities. The dimer selectivity tends to decrease with increasing phenol conversion while the selectivity to gases tends to increase with increasing phenol conversion. The product selectivities in Table 1 follow the same trends. Table 1 does not display product selectivities for a few experiments for which such data were not obtained. We developed reaction networks that were consistent with these qualitative trends in the experimental product se- 


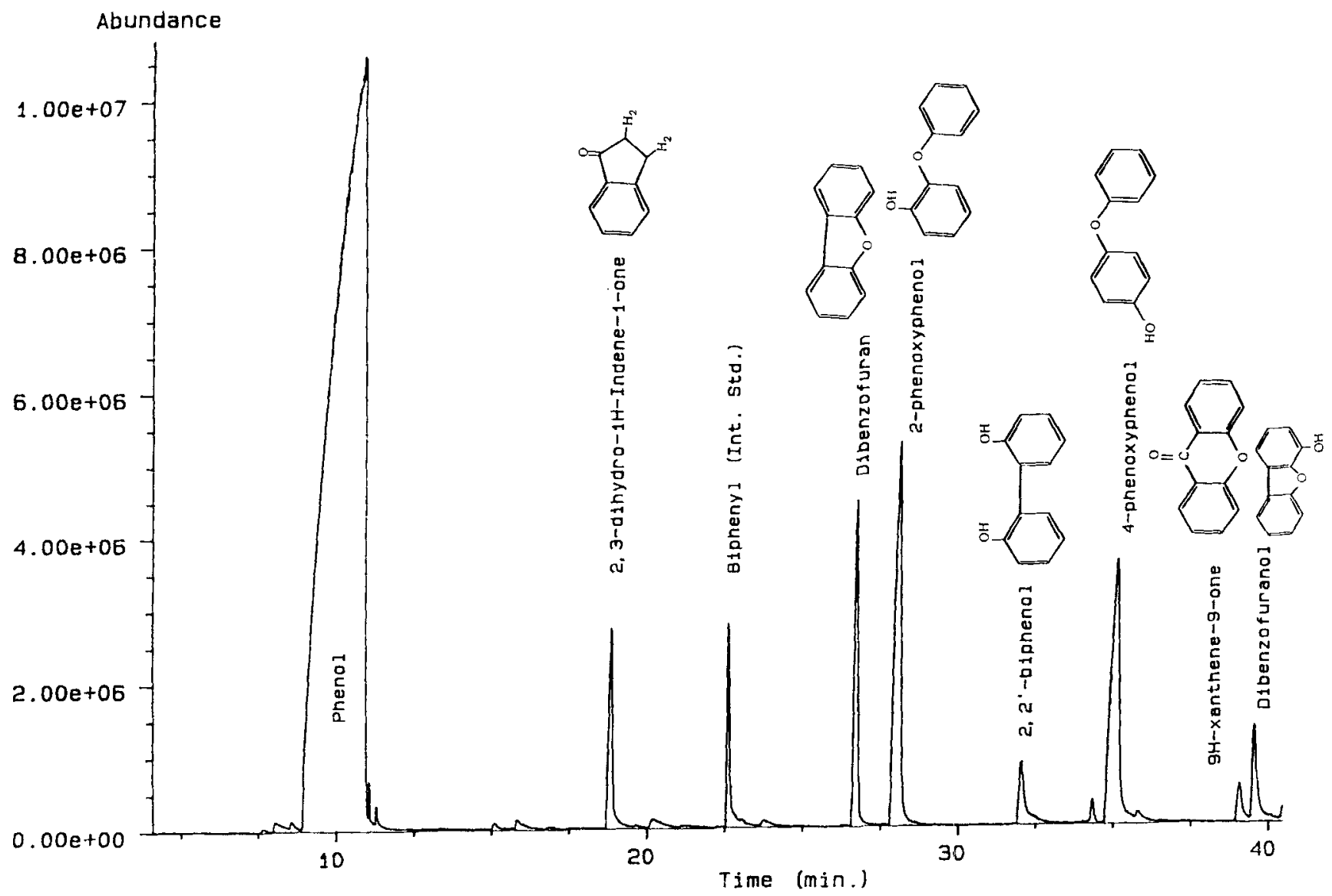

Figure 3. GC/MS total ion chromatogram of the reaction products from phenol oxidation at nominal conditions: $460^{\circ} \mathrm{C}, 250 \mathrm{~atm}, 250 \mathrm{ppm}$ phenol, $230 \%$ excess oxygen.

lectivities. We considered three such networks as shown in Figure 4 . In network 1 , phenol is consumed by parallel paths that form dimers and "other" products. The dimers either decompose to phenol or to the ring-opening and other products. Finally, the "other" products are oxidized to $\mathrm{CO}$ and $\mathrm{CO}_{2}$. Network 2 is a subset of network 1 with the rate of dimer decomposition to phenol set to zero. Network $3 \mathrm{~cm}$ ploys a slightly different lumping strategy than networks 1 and 2. The dimers are split into primary dimers (viz., phenoxyphenols and biphenol), and secondary dimers (dibenzofuran).

Li et al. (1992) proposed a qualitative global reaction network similar to Network 2, but they did not use it as a basis for a quantitative model. This network was consistent with the selectivities they had observed for dimers and single-ring products from 2-chlorophenol oxidation. Network 2 differs from the network of $\mathrm{Li}$ et al. (1992) in its product lumping strategy. $\mathrm{Li}$ et al. (1992) do not lump $\mathrm{CO}$ and $\mathrm{CO}_{2}$ into a single category as we do in the present work. In previous SCWO research, $\mathrm{CO}$ has been considered as a rate-limiting intermediate in the formation of $\mathrm{CO}_{2}$ (Helling and Tester, 1987). If this situation were true for phenol SCWO, then the relative yields of $\mathrm{CO}$ and $\mathrm{CO}_{2}$ in the current work should be governed by the global rate law for $\mathrm{CO}$ oxidation to $\mathrm{CO}_{2}$ reported by Holgate et al. (1992). Using this rate law and the same initial conditions as those used in our phenol oxidation experiments, we calculated $\mathrm{CO}$ conversions of $<25 \%$. The calculated $\mathrm{CO}$ conversion will be concentration-independent since the reaction is nearly first-order in $\mathrm{CO}$ as per the global rate law of Holgate et al. (1992). This result means that even if all of the phenol in the reactor were instantaneously oxidized to $\mathrm{CO}$ at the reactor inlet, $\mathrm{CO}$ would still constitute at least $75 \%$ of the total gas $\left(\mathrm{CO}+\mathrm{CO}_{2}\right)$ yield at the end of the reactor. But, under all the experimental conditions reported in this article, $\mathrm{CO}$ constituted only between 11 and $35 \%$ of the total gas yield. The higher $\mathrm{CO}_{2}$ yield relative to $\mathrm{CO}$ can be accounted for either by formation of $\mathrm{CO}$ and $\mathrm{CO}_{2}$ by parallel steps in the phenol oxidation network or by increased rates of $\mathrm{CO}$ oxidation to $\mathrm{CO}_{2}$ due to the presence of reactive centers derived from phenol. In either event, $\mathrm{CO}$ is not a key intermediate that determines the rate of formation of $\mathrm{CO}_{2}$. Hence, we lumped the carbon oxides together in our network model.

To discriminate between the three models, we fitted each of the models to the experimentally determined product yields. The mathematical modeling of each network involved differential equations for each of the product categories. The model for Network 1 is shown below:

$$
\begin{aligned}
\frac{d[A]}{d \tau}=-k_{1}[A]^{a_{1}}\left[\mathrm{O}_{2}\right]^{b_{1}}+k_{-1}[B]^{a_{-1}} & {\left[\mathrm{O}_{2}\right]^{b_{-1}} } \\
& -k_{2}[A]^{a_{2}}\left[\mathrm{O}_{2}\right]^{b_{2}}
\end{aligned}
$$




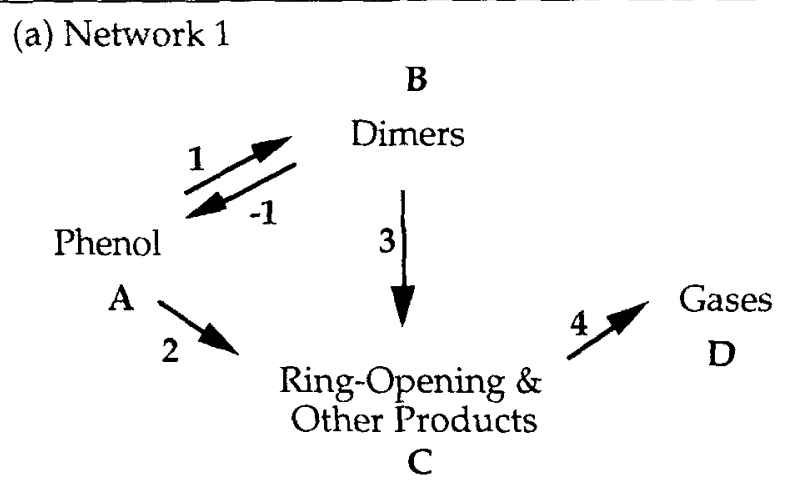

(b) Network 2

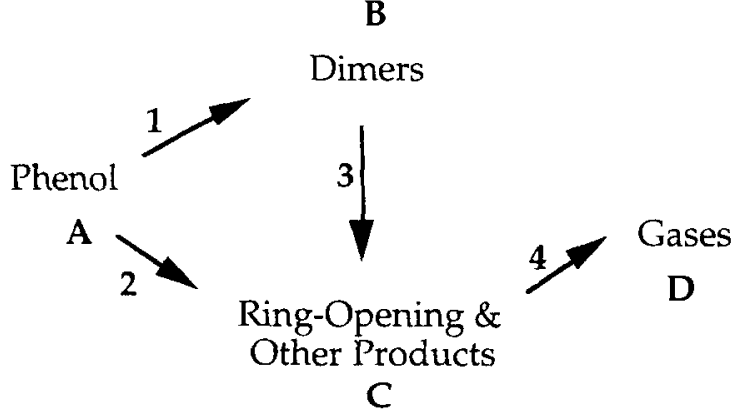

(c) Network 3

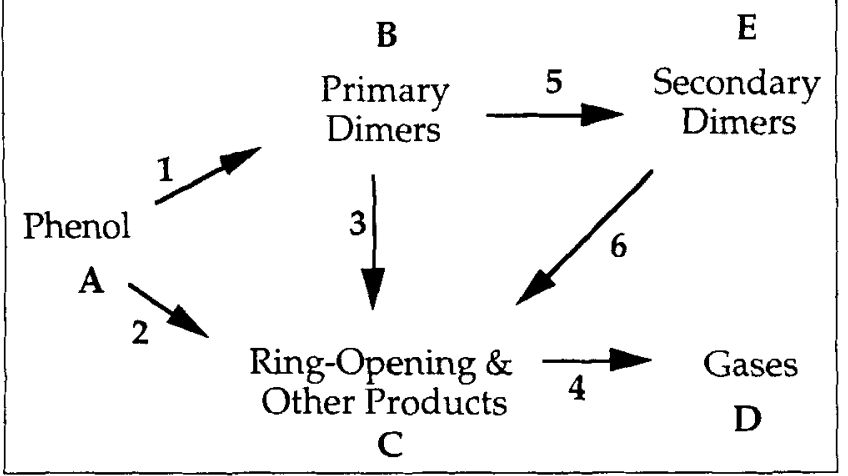

Figure 4. Proposed reaction networks to model kinetics of product formation in the supercritical water oxidation of phenol.

$$
\begin{aligned}
\frac{d[B]}{d \tau} & =k_{1}[A]^{a_{1}}\left[\mathrm{O}_{2}\right]^{b_{1}}-k_{-1}[B]^{a_{-1}}\left[\mathrm{O}_{2}\right]^{b_{-1}} \\
\frac{d[D]}{d \tau} & =k_{4}[C]^{a_{4}}\left[\mathrm{O}_{2}[B]^{a_{3}}\left[\mathrm{O}_{2}\right]^{b_{3}}\right. \\
{[C] } & =\left[A_{0}\right]-[A]-[B]-[D] .
\end{aligned}
$$

The terms within brackets are the concentrations of the entities in the network, expressed in terms of moles of carbon per unit volume. Each rate coefficient $k_{i}$ is expressed in Arrhenius form as in Eq. 2.

To determine the rate parameters for each of the four reactions in the model, we again employed SimuSolv. The parameter estimation process now incorporated an integration routine in addition to the optimization. A linear multistep predictor-corrector integration routine, LSODE, was employed in concert with the generalized reduced-gradient method. The entities for which experimental data were obtained, namely, phenol, dimers, and gases, were the response variables. The criterion for parameter estimation was the maximization of the log likelihood function for each of the response variables. As in the case of phenol disappearance kinetics, the reaction orders $\left(a_{i}, b_{i}\right)$ were determined from data at a single temperature, $460^{\circ} \mathrm{C}$. The data at $460^{\circ} \mathrm{C}$ alone were also used in the process of model discrimination. Models 1 and 2 yielded almost identical results for the estimates of their common parameters, the log likelihood function and the standard errors in response variables. In other words, reaction -1 in model 1 is kinetically insignificant, which thereby reduces model 1 to model 2 . Model 3 fit experimental yields for secondary dimers poorly, and the average difference between estimated concentrations and observed concentrations of secondary dimers was $75 \%$. Model 2 fit the experimental data best and was therefore retained for further quantitative analysis. It may be noted that Eqs. 5-8 with $k_{-1}$ set to zero describe model 2.

The reaction orders for model 2 obtained from the previous regression of data obtained at $460^{\circ} \mathrm{C}$ were then fixed in the subsequent parameter estimation. Also, the water order for each step was fixed at 0.42 , the value obtained for phenol disappearance kinetics. This water density term is not shown explicitly, but it lies buried within the Arrhenius preexponential factors in Eqs. 5-8. Because of the small range of water densities covered in the present experiments, the water order has very little impact on the quality of fit or the parameter estimates. Additionally, the present data preclude the determination of statistically significant reaction orders for water. A water order was included in the model so that we could extrapolate the model to check experimental results in the literature obtained at higher water densities (Thornton and Savage, 1992b). Data at all four temperatures $(420,440,460$ and $480^{\circ} \mathrm{C}$ ) were used to determine the Arrhenius parameters for the four individual reactions. Table 3 displays the results of the parameter estimation process for the network model 2. We elected not to display the variance-covariance matrix because it contains a large number of terms. Figures 5,6 , and 7 show parity plots of the concentrations of the response variables with different symbols to distinguish data at the four temperatures. Data in Figure 5 for phenol lie nearly on the $45^{\circ}$ line showing an excellent fit. The fit for dimers and gases is also reasonably good. We recall that the experimental uncertainty was higher for dimers than for phenol. The fit for gases (Figure 7) reflects the propagation of errors in the model.

We used the model of Figure $4 \mathrm{~b}$ with the parameters in Table 3 to predict the results of phenol SCWO reported by Thornton and Savage (1992b) and $\mathrm{Li}$ et al. (1992). Figure 8 shows a comparison of the effect of residence time on the phenol conversion and the dimer and gas yields at $380^{\circ} \mathrm{C}$ and $278 \mathrm{~atm}$. The curves, which give the model predictions, cap- 
Table 3. Parameters in Reaction Network Model

\begin{tabular}{lcccc}
\hline & Reaction 1 & Reaction 2 & Reaction 3 & Reaction 4 \\
\hline$a$ & $0.89 \pm 0.26$ & $0.86 \pm 1.19$ & $0.86 \pm 0.30$ & $0.50 \pm 0.15$ \\
$b$ & $0.49 \pm 0.23$ & $0.48 \pm 1.15$ & $0.60 \pm 0.32$ & $1.49 \pm 0.31$ \\
$E_{a}(\mathrm{kcal} / \mathrm{mol})$ & $10.0 \pm 4.7$ & $25.5 \pm 15.0$ & $28.8 \pm 4.1$ & $44.8 \pm 9.0$ \\
$A\left(\mathrm{M}^{0.58-a-b_{\mathrm{s}}{ }^{-1}}\right)^{*}$ & $10^{1.8 \pm 1.5}$ & $10^{5.6 \pm 5.5}$ & $10^{8.5 \pm 2.6}$ & $10^{13.5 \pm 2.76}$ \\
\hline
\end{tabular}

Standard Errors of Estimate

A $1.018 \mathrm{E}-05$ (moles of carbon/L)

$B \quad 1.092 \mathrm{E}-05$ (moles of carbon $/ \mathrm{L}$ )

D $1.397 \mathrm{E}-05$ (moles of carbon/L)

Pseudo-first-order Rate Constants at $460^{\circ} \mathrm{C}$ and $250 \mathrm{~atm}$

$k_{1}^{\prime}\left(s^{-1}\right) \quad 0.0256 \pm 0.0092$

$k_{2}^{\prime}\left(s^{-1}\right) \quad 0.0034 \pm 0.0001$

$k_{3}^{\prime}\left(\mathrm{s}^{-1}\right) \quad 0.3982 \pm 0.0234$

$k_{4}^{\prime}\left(\mathrm{s}^{-1}\right) \quad 0.2927 \pm 0.0545$

"M $=$ moles of carbon per liter.

ture the trends in the experimental data well. It must be noted that the conditions in Figure 8 correspond to a water density of $0.5 \mathrm{gm} / \mathrm{cm}^{3}$, which is significantly higher than the densities used in the experiments reported in this article. Incorporating a water order for the individual reactions as elaborated earlier is, in this case, necessary to extrapolate the model to this set of conditions.

\section{Strategies to reduce dimer concentrations}

The estimated activation energies in Table 3 enable us to compare the rate constants for phenol consumption along the competing parallel paths as a function of temperature. The initial dimer selectivities calculated from the model (calculated as $k_{1} / k_{1}+k_{2}$ ) range from $89 \%$ at $420^{\circ} \mathrm{C}$ to $78 \%$ at $480^{\circ} \mathrm{C}$. These rate constants when extrapolated to $600^{\circ} \mathrm{C}$ predict an initial selectivity to dimers of $\sim 45 \%$, which shows that even at higher temperatures, dimerization and ringopening reactions are likely to be equally important. Therefore, barring a change in reaction mechanism, the assertion of Swallow and Killilea (1992) that dioxins and furans would

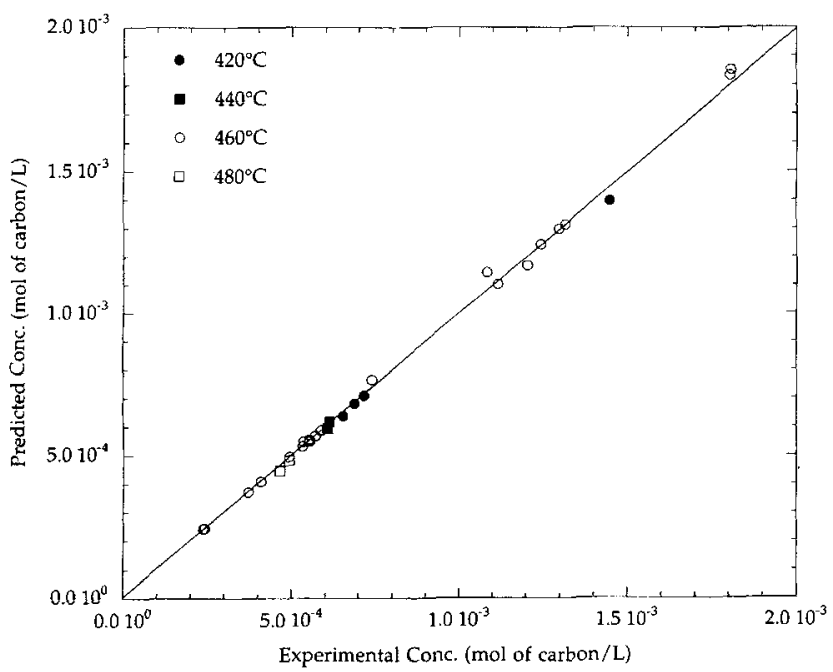

Figure 5. Parity plot of model calculations of phenol concentrations against experimental values.

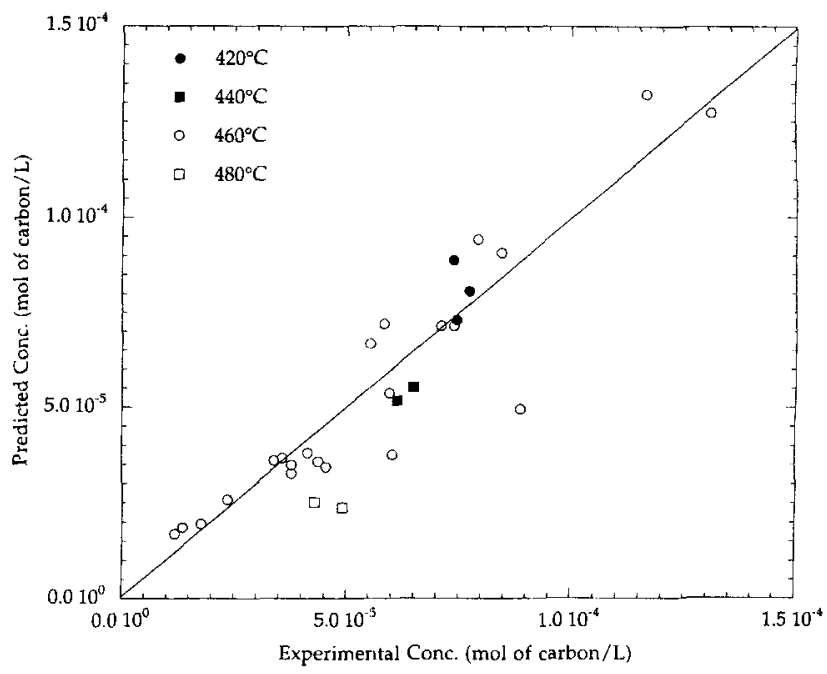

Figure 6. Parity plot of model calculations of dimer concentrations against experimental values.

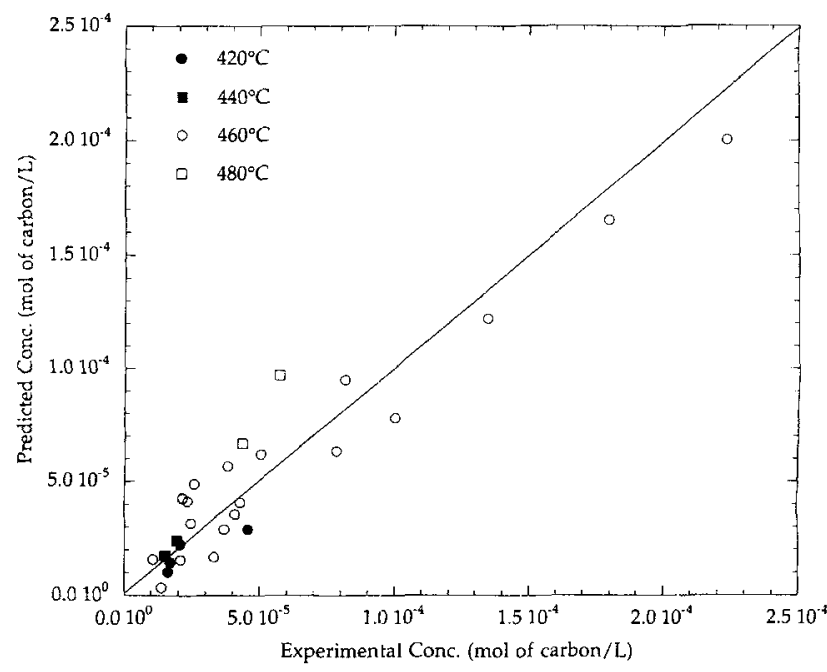

Figure 7. Parity plot of model calculations of gas concentrations against experimental values. 


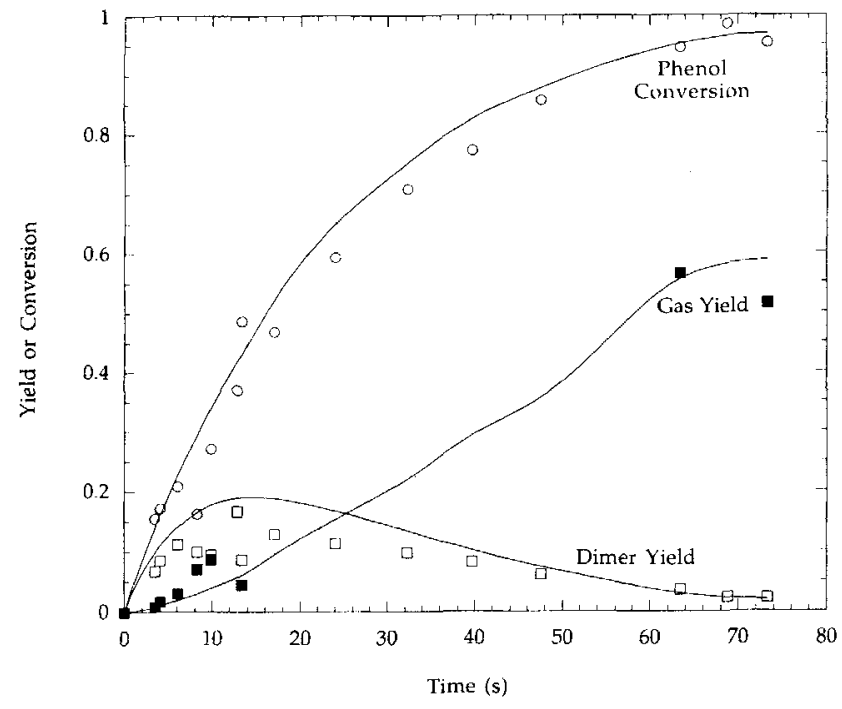

Figure 8. Profiles of model predictions of phenol conversion and product yields.

Expermental data from Thornton and Savage (1992b) and Li et al. (1992) at nominal conditions: $380^{\circ} \mathrm{C}, 278 \mathrm{~atm}, 100$ ppm phenol, $800 \%$ excess oxygen.

not form from phenols at high temperatures appears unlikely. It appears more likely that they form but are rapidly destroyed. These initial selectivity results along with the dimer yields displayed in Figure 8 show that dimerization is the main primary pathway for phenol. Reaction path 2 (see Figure 4b) being much less important than path 1 also accounts for the higher standard deviations in the estimates of the kinetics parameters for reaction 2 . Consequently, the initial dimer selectivities calculated from the model also have associated uncertainties. The initial selectivity data are presented solely to illustrate that dimerization is the major primary path for phenol oxidation at temperatures between 380 and $480^{\circ} \mathrm{C}$.

The model also shows that although the formation of dimers cannot be prevented, the dimer yield decreases with increasing phenol conversion after going through a maximum mation of gases $(45 \mathrm{kcal} / \mathrm{mol})$ exceeding the activation energies for the steps leading to the formation of the ring-opening and other intermediates $(25$ and $29 \mathrm{kcal} / \mathrm{mol})$. Products of ring-opening reactions such as acetic acid (Lee et al., 1990) have been considered to be refractory and hence rate-limiting intermediates for supercritical water oxidation. A comparison of the pseudo-first-order rate constants for the four steps at $460^{\circ} \mathrm{C}$ (see Table 3), however, reveals that along the dominant route of reactions 1,3 , and 4 in series, dimerization of phenol is the slowest reaction $\left(k_{1}^{\prime}<k_{2}^{\prime}, k_{3}^{\prime}\right)$. Therefore, there are no refractory intermediates in the SCWO of phenol at $460^{\circ} \mathrm{C}$.

The reaction orders for phenol in Table 3 for the two primary paths are nearly equal, so varying the phenol concentration will have little effect on the product selectivities. The reaction orders for oxygen are also nearly equal for all the steps except for step 4, which has an oxygen order of 1.5. This high oxygen order indicates that high oxygen concentrations will result in higher rates of formation of gases.

$\mathrm{Li}$ et al. (1992) reported a rate law for the formation of $\mathrm{CO}_{2}$ from phenol based on total organic carbon (TOC) content at temperatures between 300 and $420^{\circ} \mathrm{C}$. We extrapolated this rate law to predict $\mathrm{CO}_{2}$ yields from the experiments in Table 1. Their rate law worked just as well at our higher temperatures as it did at their lower temperatures. There were no systematic errors discernible from the residuals. This agreement was obtained even though the activation energy for the formation of gases in the present network model $(45 \mathrm{kcal} / \mathrm{mol})$ is much greater than the activation energy of $6.2 \mathrm{kcal} / \mathrm{mol}$ reported by $\mathrm{Li}$ et al. (1992) for the formation of $\mathrm{CO}_{2}$. The activation energies and other kinetic parameters from these two approaches need not be equal and cannot be compared because they were obtained for two different global reaction schemes.

\section{Summary and Conclusion}

(1) The kinetics data and product selectivities that we report for the SCWO of phenol extend our knowledge of this system to higher temperatures. The kinetic of phenol disappearance were best fit by the global rate law

$$
\text { rate }=10^{2.34 \pm 0.28} \exp \left(-\frac{12.4 \pm 1.0}{R T}\right)[\phi \mathrm{OH}]^{0.85 \pm 0.04}\left[\mathrm{O}_{2}\right]^{0.50 \pm 0.05}\left[\mathrm{H}_{2} \mathrm{O}\right]^{0.42 \pm 0.05}
$$

(Figure 8). At complete conversion of phenol, the dimer yield is essentially zero. Also, the destruction of dimers is aided by higher temperatures as is evident from the activation energy for the destruction of dimers $(29 \mathrm{kcal} / \mathrm{mol})$ exceeding that for dimer formation $(10 \mathrm{kcal} / \mathrm{mol})$. This difference in activation energies translates to an increase in the ratio of the rate constant for destruction of dimers to that for the formation of dimers $\left(k_{3} / k_{1}\right)$ by a factor of 7 when the temperature increases from 380 to $480^{\circ} \mathrm{C}$.

The parameters in Table 3 also show that higher temperatures have the desirable effect of favoring the formation of gases. This is evident from the activation energy for the for- where the reaction rate has units of $\mathrm{mol} \mathrm{L}^{-1} \mathrm{~s}^{-1}$, concentrations are in $\mathrm{mol} \mathrm{L}^{-1}$, and the activation energy is in $\mathrm{kcal} / \mathrm{mol}$. The uncertainties represent standard deviations. The parameters in this rate law are more precise than those reported previously by Thornton and Savage (1992a).

(2) The products of phenol oxidation in SCW can be categorized as dimers, gases, and ring-opening and other products. The variation of the selectivity of phenol to these products with residence time, temperature, and species concentrations can be quantitatively described using the reaction network in Figure $4 \mathrm{~b}$ and the parameters in Table 3 . The network includes parallel pathways for phenol to dimers and 
to ring-opening and other products, secondary decomposition of dimers to ring-opening and other intermediates, and oxidation of these intermediates to carbon oxides.

(3) Dimerization of phenol is the main primary pathway for phenol consumption between 380 and $480^{\circ} \mathrm{C}$. A successful strategy for treatment of phenolic wastes by SCWO must ensure the destruction of these dimers and the formation of $\mathrm{CO}_{2}$ in high selectivities. Our quantitative reaction model showed that long residence times and high reaction temperatures favor the destruction of dimers and the formation of $\mathrm{CO}$ and $\mathrm{CO}_{2}$. Moreover, the influence of intermediate reaction products (dimers and other products) on the rate of formation of the carbon oxides shows that phenol disappearance kinetics alone constitutes insufficient information for process design. Identifying and quantifying reaction intermediates and developing accurate quantitative reaction models is of vital importance for any rational SCWO process design.

\section{Acknowledgments}

Our research in SCWO has been supported by the NSF (CTS9015738), EPA (R817857-01-O), and DOE (DE-FG22-92PCG92536).

\section{Notation}

$P_{c}=$ critical pressure

$R=$ gas constant

$T_{c}=$ critical temperature

\section{Subscripts and Superscripts}

$$
\begin{aligned}
c & =\text { critical } \\
, & =\text { pseudo-first-order }
\end{aligned}
$$

\section{Literature Cited}

Antal, M. J., A. Brittain, C. DeAlmeida, S. Ramayya, and J. C. Roy, "Heterolysis and Homolysis in Supercritical Water," ACS Symps. Ser., 329, 77 (1987).

Crain, N., S. Tebbal, L. Li, and E. F. Gloyna, "Kinetics and Reaction Pathways of Pyridine Oxidation in Supercritical Water," Ind. Eng. Chem. Res., 32, 2259 (1993).

Cutler, A. H., M. J. Antal, and M. Jones, "A Critical Evaluation of Tubular-Flow Reactor Data," Ind. Eng. Chem. Res., 27, 691 (1988). Federal Register, "Method 604-Phenols," 49, 43290 (1984).

Héberger, K., S. Kemény, and T. Vidóczy, "On the Errors of Arrhe- nius Parameters and Estimated Rate Constant Values," Int. $J$. Chem. Kinet., 19, 171 (1987).

Helling, R. K., and J. W. Tester, "Oxidation Kinetics of Carbon Monoxide in Supercritical Water," Energy \& Fuels, 1, 417 (1987).

Holgate, H. R., P. A. Webley, J. W. Tester, and R. K. Helling, "Carbon Monoxide Oxidation in Supercritical Water: The Effects of Heat Transfer and the Water-Gas Shift Reaction on Observed Kinetics," Energy \& Fuels, 6, 586 (1992).

Lee, D. S., E. F. Gloyna, and L. Li, "Efficiency of $\mathrm{H}_{2} \mathrm{O}_{2}$ and $\mathrm{O}_{2}$ in Supercritical Water Oxidation of 2,4-Dichlorophenol and Acetic Acid," J. Supercrit. Fluids, 3, 249 (1990).

Li, R., T. D. Thornton, and P. E. Savage, "Kinetics of $\mathrm{CO}_{2}$ Formation from the Oxidation of Phenols in Supercritical Water," Env. Sci. Technol., 26, 2388 (1992).

Li, R., P. E. Savage, and D. Szmukler, "2-Chlorophenol Oxidation in Supercritical Water: Global Kinetics and Reaction Products," AIChE J., 39, 178 (1993).

Modell, M., "Supercritical-Water Oxidation," in Standard Handbook of Hazardous Waste Treatment and Disposal, Sec 8.11, H. M. Freeman, ed., McGraw-Hill, New York (1989).

Rice, S. F., R. R. Steeper, and C. A. LaJeunesse, "Destruction of Representative Navy Wastes using Supercritical Water Oxidation," Sandia Rep. SAND94-8203 (1993).

Savage, P. E., and M. A. Smith, "Kinetics of Acetic Acid Oxidation in Supercritical Water," Environ. Sci. Technol., 29, 216 (1995).

Steiner, E. C., T. D. Rey, and P. S. McCroskey, "SimuSolv Modeling and Simulation Software Reference Guide," The Dow Chemical Company, Midland, MI (1990).

Swallow, K. C., and W. R. Killilea, "Comment on 'Phenol Oxidation in Supercritical Water: Reaction Kinetics, Products, and Pathways',"Environ. Sci. Technol, 26, 1849 (1992).

Thornton, T. D., and P. E. Savage, "Phenol Oxidation in Supercritical Water," J. Supercrit. Fluids, 3, 240 (1990).

Thornton, T. D., "Phenol Oxidation in Supercritical Water: Reaction Kinetics, Products, and Pathways," PhD Thesis, The University of Michigan, Ann Arbor (1991).

Thornton, T. D., D. E. LaDue, and P. E. Savage, "Phenol Oxidation in Supercritical Water: Formation of Dibenzofuran, Dibenzo-p-dioxin, and Related Compounds," Env. Sci. Technol., 25, 1507 (1991).

Thornton, T. D., and P. E. Savage, "Kinetics of Phenol Oxidation in Supercritical Water," AIChE J., 38, 321, (1992a).

Thornton, T. D., and P. E. Savage, "Phenol Oxidation Pathways in Supercritical Water," Ind. Eng. Chem. Res, 31, 2451 (1992b).

Wightman, T. J., "Studies in Supercritical Wet Air Oxidation," MS Thesis, University of California, Berkeley (1981).

Yang, H. H., and C. A. Eckert, "Homogeneous Catalysis in the Oxidation of $p$-Chlorophenol in Supercritical Water," Ind. Eng. Chem. Res., 27, 2009 (1988).

Manuscript received May 31, 1994, and revision received Sept. 6, 1994. 